\title{
Elbow Dislocation with Ipsilateral Diaphyseal Forearm Fracture : A Rare Combination
}

\section{Essekkal M*, baataoui A and Boutayeb F \\ Department of Orthopaedic Surgery, Hassan 2 Hospital, Morocco}

Submission: March 13, 2018; Published: April 09, 2018

*Corresponding author: Essekkal M, Department of Orthopaedic Surgery, Hassan 2 Hospital, Casablanca, Morocco,

Email: essekkalmohamed@gmail.com

\begin{abstract}
Dislocation of the elbow with shaft fractures of both bones of the ipsilateral forearm is a rare injury although elbow dislocation and forearm fractures may occur separately. We report a case of an 30-year-old men who had a posterior elbow dislocation and ipsilateral radial and ulnar shaft fractures and underwent closed reduction and plate fixation.
\end{abstract}

Keywords: Elbow; Dislocation; Fracture; Forearm

\section{Introduction}

The "terrible triad" of the elbow, consisting of a posterior dislocation together with a fracture of the coronoid process and the radial head, has been described before [1-2]. Ulnar diaphyseal forearm fracture associated with radial head dislocation has also been described before as the Monteggia fracture-dislocation [24]. However, elbow dislocations with concurrent fractures of both the ipsilateral radius and ulnar diaphyses are rare injuries. A few case reports have been published on this particular type of injury [1-5].

\section{Case Report}

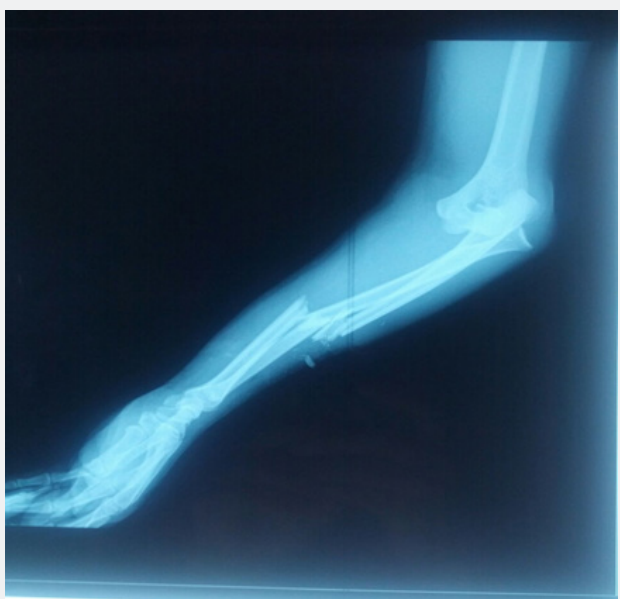

Figure 1: Preoperative anteroposterior.
A 30 years old gentleman presented to the surgical emergency room with a history of fall from a motorbike and was supporting her right upper limb with the left hand. On physical examination, both the right elbow and the forearm were grossly deformed. There was no neurovascular compromise. Radiographs revealed left radius and ulnar shaft fracture with posterior elbow dislocation (Figures 1 \& 2) Closed reduction of the elbow was done under sedation in the emergency room and a back slab was applied; the need for operative fixation of the fractures was explained to the patient, he was taken up for surgery $12 \mathrm{~h}$ after presentation.

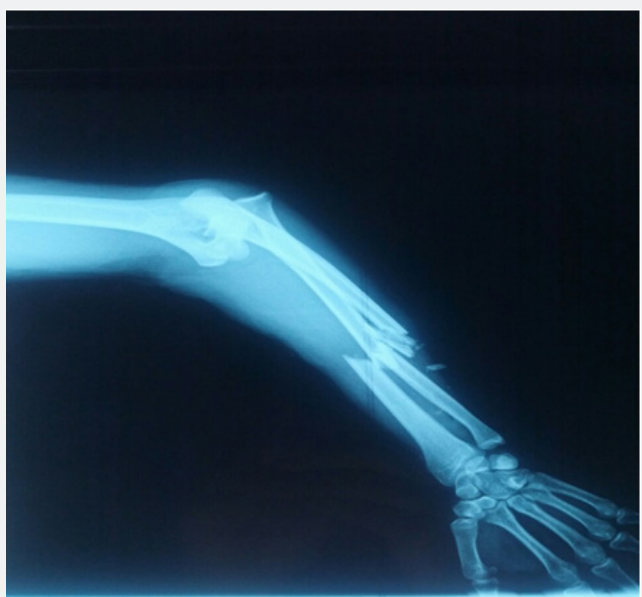

Figure 2: Lateral Radiographs. 
Internal fixation of the radius was done with an 6-hole $3.5 \mathrm{~mm}$ dynamic compression plate (DCP) using the volar approach of Henry. Similarly, ulna was fixed with 8 -hole 1/3 tube from dorsal approach. Postoperative radiographs demonstrated satisfactory reduction of the fractures and the elbow dislocation (Figure 3 \& 4).

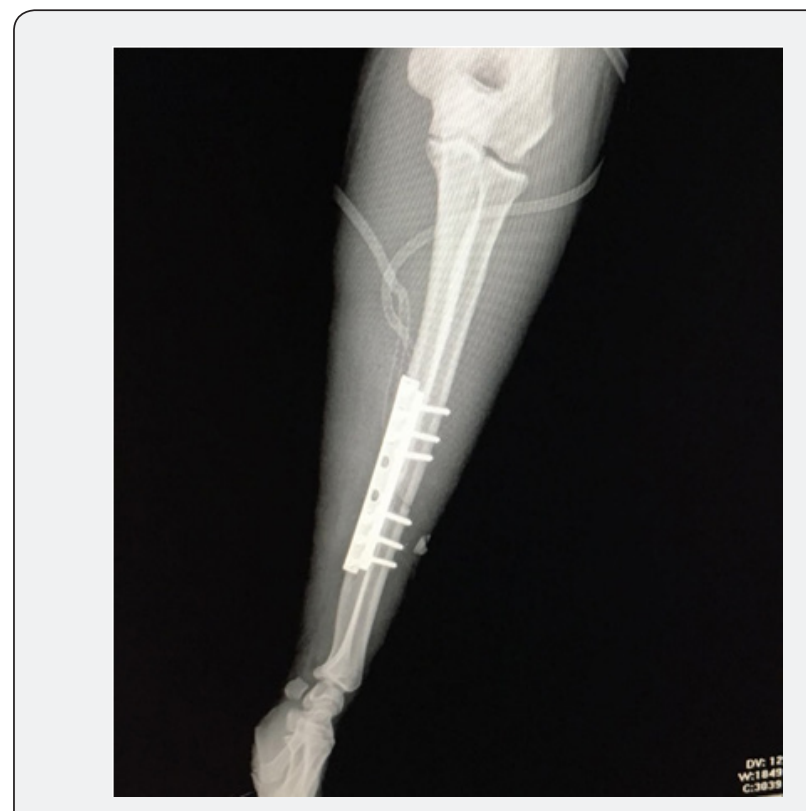

Figure 3: Postoperative images showing reduction.

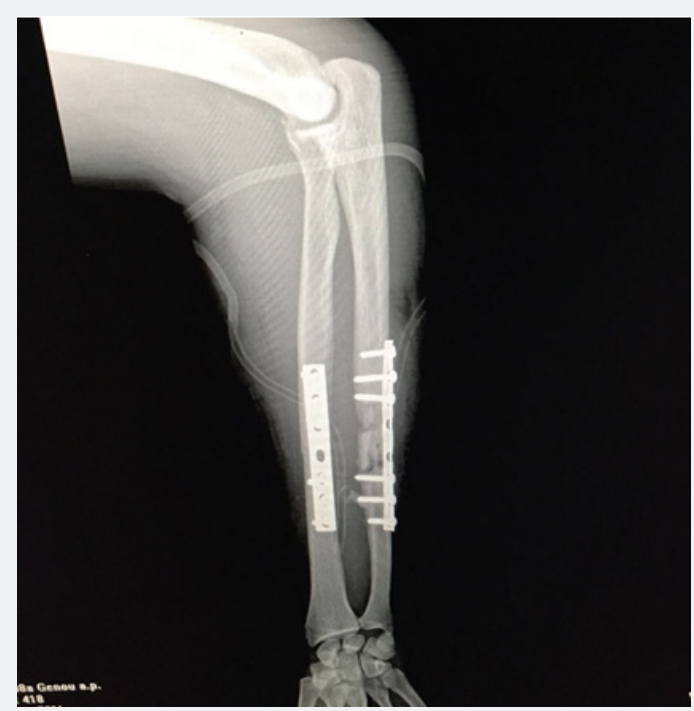

Figure 4: Postoperative images showing fracture fixation.

\section{Discussion}

The elbow joint is a stable diarthroidal articulation of the human skeleton [2-4], Fractures of forearm bones associated with elbow dislocation commonly occur around the elbow [3-5] but a combination of elbow dislocation and ipsilateral diaphyseal fractures of the radius and ulna is a rare injury as the force required to produce this injury is likely to be significantly greater than that required for a simple elbow dislocation or a fracture of forearm bones alone $[6,7]$.

Kose et al. [6,7], have postulated the mechanism of injury to be two staged in which initial elbow dislocation resulting from a fall on outstretched hand is followed by fractures of both the bones of forearm while the elbow was still in extension, the forearm in hyper-pronation and the wrist in radial deviation, The probability of the sequence being reverse is highly unlikely as once the forearm bones are fractured, the force needed to cause elbow dislocation cannot be transmitted up to the elbow.

\section{Conclusion}

In conclusion, Elbow dislocation with ipsilateral radial and ulnar shaft fractures is rare. The radiographs must always include the elbow and the wrist joints Reduction and internal fixation are necessary to obtain good functional.

\section{References}

1. Bado JL (1967) The Monteggia lesion. Clin Orthop 50: 71-86.

2. CD Bryce AD (2008) Armstrong Anatomy and biomechanics of the elbow. Orthop Clin North Am 39(2): 141-154.

3. D Ring, JB Jupiter (1998) Fracture-dislocation of the elbow. J Bone Jt Surg Am 80(4) : 566-580.

4. Hotchkiss RN (1966) Fractures and dislocations of the elbow. In: Rockwood CA, Green DP, Heckman RW, Bucholz JD, (Eds.), Rockwood and Green's fractures in adults. Lippincott Williams \& Wilkins, Philadelphia, USA, pp. 980-981.

5. Hung SC, Huang CK, Chiang CC, Chen TH, Chen WM, et al. (2003) Monteggia type 1 equivalent lesion: diaphyseal ulna and radius fractures with a posterior elbow dislocation in an adult. Arch Orthop Trauma Surg 123(6): 311-313.

6. Kose O, Durakbasa MO, Islam NC (2008) Posterolateral elbow dislocation with ipsilateral radial and ulnar diaphyseal fractures: a case report J Orthop Surg (Hong Kong) 16(1): 122-123.

7. Hung SC, Huang CK, Chiang CC, Chen TH, Chen WM, et al. (2003) Monteggia type I equivalent lesion: diaphyseal ulna and radius fractures with a posterior elbow dislocation in an adult. Arch Orthop Trauma Surg 123(6): 311-313. 


\section{Your next submission with Juniper Publishers} will reach you the below assets

- Quality Editorial service

- Swift Peer Review

- Reprints availability

- E-prints Service

- Manuscript Podcast for convenient understanding

- Global attainment for your research

- Manuscript accessibility in different formats

( Pdf, E-pub, Full Text, Audio)

- Unceasing customer service

Track the below URL for one-step submission https://juniperpublishers.com/online-submission.php 